
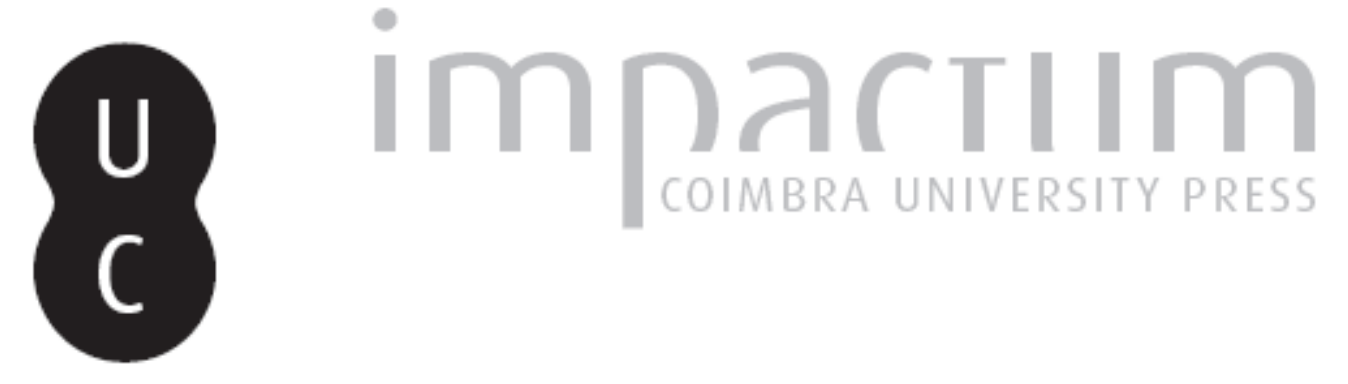

Segurança humana e protecção civil na sociedade do risco: a crise do estatocêntrico na(s) segurança(s)

\author{
Autor(es): \\ Amaro, António
}

Publicado por: Associação Portuguesa de Riscos, Prevenção e Segurança

URL persistente:

URI:http://hdl.handle.net/10316.2/36199

DOI:

DOI:http://dx.doi.org/10.14195/1647-7723_15_7

Accessed : $\quad$ 26-Apr-2023 13:24:52

A navegação consulta e descarregamento dos títulos inseridos nas Bibliotecas Digitais UC Digitalis, UC Pombalina e UC Impactum, pressupõem a aceitação plena e sem reservas dos Termos e Condições de Uso destas Bibliotecas Digitais, disponíveis em https://digitalis.uc.pt/pt-pt/termos.

Conforme exposto nos referidos Termos e Condições de Uso, o descarregamento de títulos de acesso restrito requer uma licença válida de autorização devendo o utilizador aceder ao(s) documento(s) a partir de um endereço de IP da instituição detentora da supramencionada licença.

Ao utilizador é apenas permitido o descarregamento para uso pessoal, pelo que o emprego do(s) título(s) descarregado(s) para outro fim, designadamente comercial, carece de autorização do respetivo autor ou editor da obra.

Na medida em que todas as obras da UC Digitalis se encontram protegidas pelo Código do Direito de Autor e Direitos Conexos e demais legislação aplicável, toda a cópia, parcial ou total, deste documento, nos casos em que é legalmente admitida, deverá conter ou fazer-se acompanhar por este aviso.

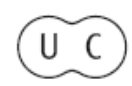




\section{territorium}

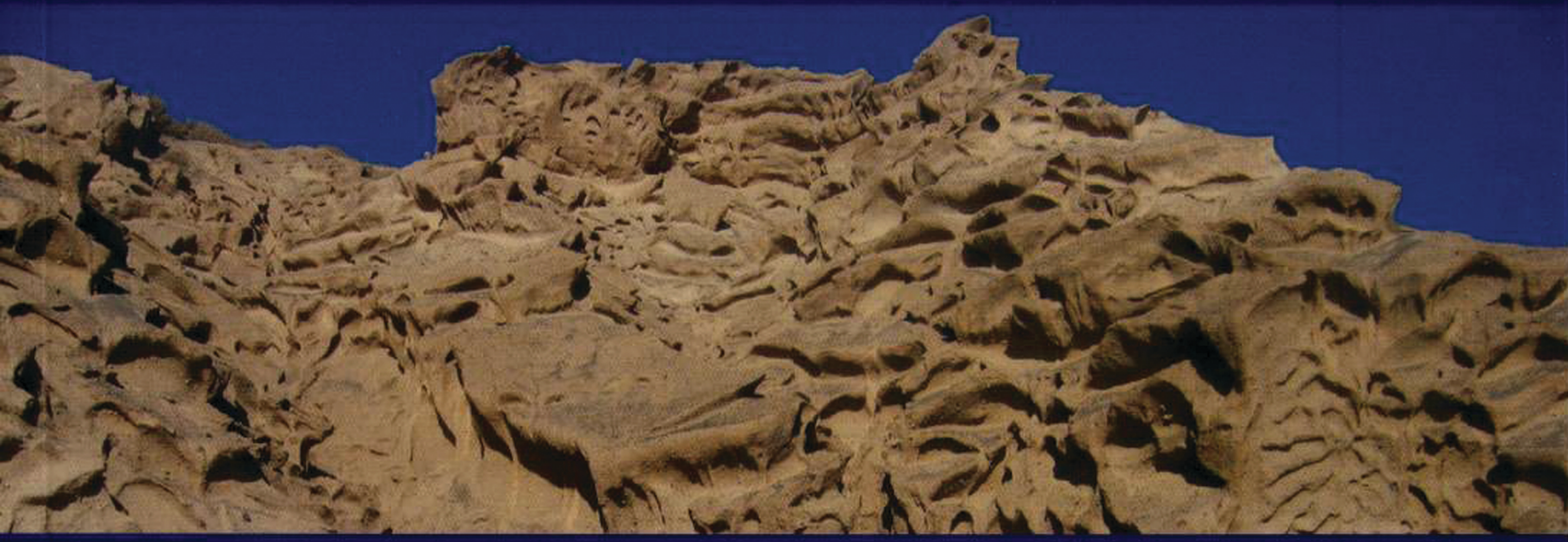

15

Revista da Associação Portuguesa de Riscos, Prevenção e Segurança 2008 
pp. $83-94$

\title{
SEGURANÇA HUMANA E PROTECÇÃO CIVIL NA SOCIEDADE DO RISCO: A CRISE DO MODELO ESTATOCÊNTRICO NA(S) SEGURANÇA(S) *
}

\author{
António Amaro \\ amaro@essa.pt \\ Director da Escola Superior de Saúde do Alcoitão, Sociólogo
}

\section{RESUMO}

O Estado estatocêntrico tem condições para garantir, por si só, a segurança humana face à grande diversidade de vulnerabilidades sociais e ecológicas? O modelo de gestão humanocêntrico é mais adequado à protecção dos cidadãos na sociedade contemporânea? Ou seja, no centro está a protecção dos cidadãos ou dos Estados? A Protecção Civil baseada em bombeiros voluntários tem condições para proteger e socorrer, com prontidão os cidadãos?

Palavras-chave: Segurança humana, sociedade de risco, protecção civil, bombeiros.

\begin{abstract}
In a risk society can a government-centered model of civil protection on his own guarantee the human security in the face of an increasing diversity of social and ecological vulnerabilities? Does a citizen centered-model guarantee more protection in a modern society? In other words what is the priority the citizen or the government? Can the civil protection and its "armed forces", the volunteer firefighters protect and rescue the citizens with promptitude?
\end{abstract}

Key words: Human security, risk society, civil protection, firefighters.

\section{RÉSUMÉ}

L'Etat centralisateur aura-t-il conditions pour garantir, seulement, la sécurité humaine en face de la grande diversité de vulnérabilités sociaux et ecologiques? Le modèle de gestion qui a la personne humaine au centre c'est le mieu pour la protection des citoyens dans la societé contemporaine? Qui est au centre de la societé: I'Etat ou les citoyens? La proteccion civile basée sur pompiers voluntaires aura-t-elle conditions pour garantir le secours avec promptitude?

Mots clés: Securité humaine, societé de risques, proteccion civile, pompiers.

* Comunicação apresentada ao IV Encontro Nacional de Riscos, Coimbra, 10 de Março de 2008. 
A Segurança tem sido sempre considerada uma competência do Estado. Efectivamente, desde que o conceito começou a ser utilizado, a partir do século $\mathrm{XVII}$, o Estado é a entidade que detém como numa das suas atribuições fundamentais, o monopólio do uso da violência e os meios para a protecção e segurança dos cidadãos. O seu poder ampliou-se com vista a garantir a ordem e a paz, outra das competências fundamentais do Estado moderno. Naturalmente, e podemos historicamente comproválo, o Estado esteve, muitas vezes, ao longo dos últimos três séculos, ocupado em manter a lei e a ordem e certas condições políticas e jurídicas de uma parte da sociedade, constituída em poder dominante, em detrimento de outras. (PereIRA, 2006:143)

Hoje, o Estado encontra-se num processo de "reforma", no quadro de um mundo cada vez mais interdependente e globalizado, que obriga ao repensar e redefinir das estruturas, conceitos e funções do Estado designadamente em matéria de segurança e da relação desta com a cidadania.

O conceito tradicional de segurança tende a aparecer normalmente associado à manutenção da ordem pública e ao controle da criminalidade. Ora, as pessoas, os cidadãos, exprimem e experimentam hoje preocupações e sentimentos de insegurança e incerteza da sua vida quotidiana, seja a nível do trabalho, da saúde e do ambiente. Estamos perante demandas de segurança, de ordem múltipla e multifactorial, que um conceito mais amplo poderá explicar: o conceito de Segurança Humana. $O$ conceito de Segurança Humana, assevera PereIRA (2006:17) surge pela primeira vez, em 1994, num dos documentos do PNUD (Programa das Nações Unidas para o Desenvolvimento) e a partir daí, não tem deixado de marcar presença em numerosos âmbitos de índole académica, política e social. É uma noção ampla, multidimensional, que atravessa vários campos, centrada nas pessoas e nas comunidades, mais que nos Estados.

Nesta perspectiva, a segurança deixou de ser um tema exclusivo dos Estados. Para a sociedade civil e para as pessoas em geral, a segurança humana converteuse num assunto central do seu bem-estar e segurança e para o funcionamento de uma sociedade baseada na liberdade e na convivência social. Ou seja, na sua acepção mais ampla, a segurança humana representa muito mais que a ausência de violência. Abarca o cumprimento dos direitos humanos, a gestão e regulação por parte do Estado dos riscos relativos à saúde, à participação das comunidades e a prevenção dos conflitos. Em síntese, o conceito tem muitas caras e dimensões, desde o terrorismo (fot. 1) ao ambiente (fot. 2).

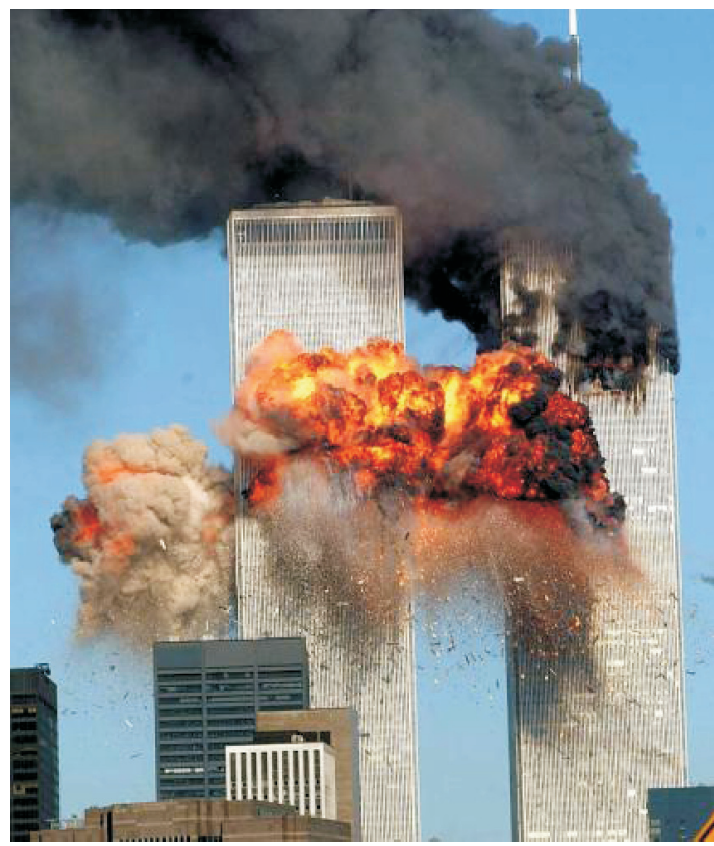

Fot. 1 - Ataque às Torres Gémeas (fonte: www.mirrors.org).

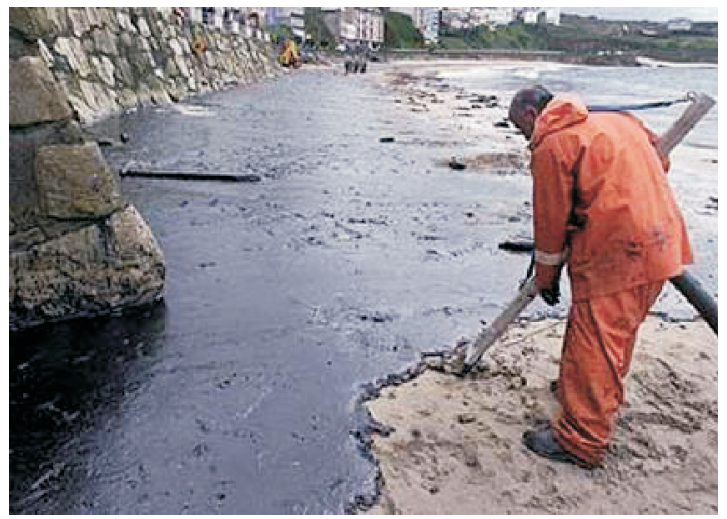

Fot. 2 - Derrame provocado pelo Prestige (fonte: www.youngreporters.org).

Nalguns casos estamos a falar de segurança política frente a abusos e violações de direitos humanos; de segurança pessoal e individual face à criminalidade e à violência contra as mulheres, ou face ao terrorismo; noutros trata-se de segurança ambiental e ecológica face à degradação do ar, água, terra e florestas (os chamados bens públicos globais); ou ainda segurança alimentar frente à escassez de alimentos ou aos riscos derivados de produtos perigosos para a saúde humana; também a segurança frente a doenças e enfermidades novas e transmissíveis e as enfermidades respiratórias produzidas pela contaminação; finalmente, segurança económica frente ao trabalho precário e à desigualdade de rendimentos. Estamos perante um conceito integrador, 
humanocêntrico que tem a sua génese na luta pelos direitos humanos, e por uma vida digna e plena para todos, ao nível ambiental, industrial, alimentar, segurança ante novos riscos tecnológicos e novas formas de trabalho, e não unicamente o fundamento da ordem, ou seja, a perspectiva estatocêntrica a qual deve ceder passo à perspectiva humanocêntrica, introduzindo a segurança humana como eixo integrador das políticas públicas.

Fundamentalmente, a segurança humana significa uma vida livre de ameaças profundas aos direitos das pessoas, à sua segurança e das próprias vidas. A segurança humana implica proteger as liberdades vitais, proteger as pessoas expostas às ameaças e a situações difíceis, de tal modo que se possam criar sistemas com dispositivos de sobrevivência, dignidade e meios de vida. Isto é, a segurança humana não está só relacionada com a ordem pública e a garantia do cumprimento das leis, mas abarca outras dimensões do ser humano e da relação deste com o seu contexto social e natural, apelando não só à protecção, como também à prevenção e à habilitação das pessoas para valerem-se a si mesmas em situação de vulnerabilidade (fot. 3).

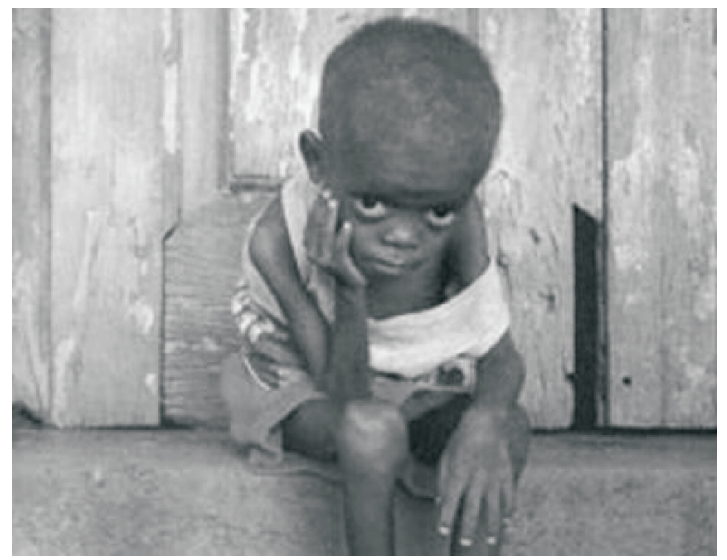

Fot. 3 - Mudança de paradigma na Segurança Humana (fonte: http://caldeiraodebolsa.jornaldenegocios.pt).

Neste quadro, o conceito de segurança humana articula-se, diria mesmo, integra-se, no conceito de vulnerabilidade social ou vulnerabilidade da segurança humana na sociedade de risco. (MENDES, 2007:33-34)

A teorização dos novos riscos e da "sociedade de risco" não surge, assim, por acaso. Uma das ideias fundamentais de ULRICH BECK, (1992) autor ao qual é atribuída a paternidade deste conceito, é a de que na "modernidade avançada" a produção social de riqueza é sistematicamente acompanhada pela produção social de novos riscos.
Beck sugere que aos conflitos da sociedade industrial que se centravam, sobretudo, na distribuição de recursos escassos, somam-se hoje outros conflitos que incidem sobre a produção, a definição e a distribuição dos riscos causados pelo próprio sistema industrial e tecnológico. Giddens refere-se, por seu lado, aos riscos "manufacturados" pela aplicação da tecnologia (GIDDENS, 1998: 35).

Os novos riscos são qualitativamente diferentes dos riscos da sociedade industrial. Embora reconhecendo que os países pobres são naturalmente mais vulneráveis aos riscos do que aos países ricos, Beck considera que os riscos tendem a ser "globais" como os resultantes de mudanças climáticas (fot. 4) transcendendo as fronteiras nacionais, afectando potencialmente toda a humanidade e todas as formas de vida animal e vegetal (BECK, 1992: 21, 22).

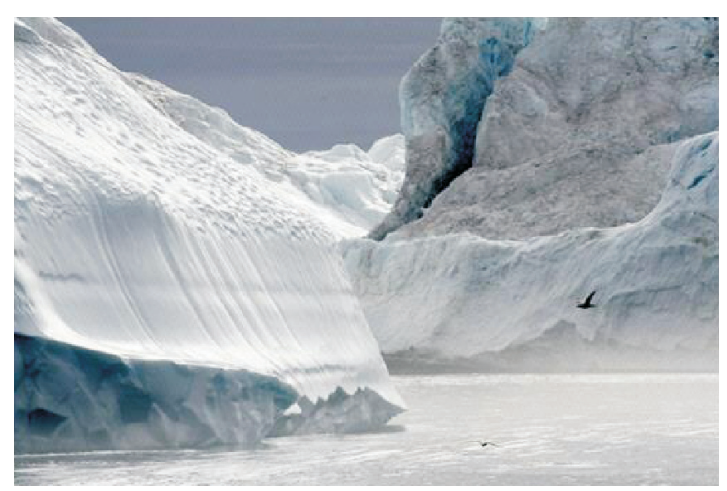

Fot. 4 - Mudanças climáticas (Fonte: http://d.yimg.com/br.yimg.com/pi/ news/afp/i/071116/isgeait49161107113805photo00.jpg).

Este entendimento não é indiferente ao facto de os riscos serem indissociáveis dos processos da globalização económica e social. Eles escapam do mesmo passo às instituições de controlo e protecção da sociedade industrial e dos Estados. Uma outra ideia central é que os cidadãos se tornam cada vez mais "socialmente reflexivos", deixando de aceitar sem discussão novas tecnologias ou novos modelos produtivos. Os riscos tendem a dominar o debate público, dando origem a novos tipos de conflitos e controvérsias (BECK, 1994: 27).

A sociedade parece revelar, inclusivamente, uma hipersensibilidade ao risco, tomando consciência de que os recursos que constituem a base da riqueza das sociedades estão cada vez mais poluídos e de que crescem as forças destrutivas. Deixa, assim, de se preocupar tão-só com os usos da Natureza de forma utilitária, como até agora, para se preocupar, cada vez mais, com as consequências gravosas do próprio desenvolvimento urbano-industrial (GONÇALVES, 2003:94). 
Uma das razões que explicam que as questões do ambiente, da saúde pública e do consumo tenham sido tão politizadas nos últimos tempos reside, precisamente, no facto de colocarem em cima da mesa a questão do sistema político e da organização dos processo de decisão. As controvérsias sobre os riscos tornam-se, assim, eixos centrais em torno dos quais ocorrem as transformações sociais e políticas. Por outras palavras, os riscos são social e "politicamente reflexivos"; contendo em si os ingredientes de uma profunda crise do sistema político, incluindo da relação entre a ciência e os processos políticos, que têm caracterizado o mundo ocidental (BECK, 1992: 21), tornando, por isso, necessárias novas formas de regulação pública dos sistemas produtivos (BECK, 1992:21).

Os trabalhos de Beck demonstram que apesar dos mundos naturais e sociais serem progressivamente melhor conhecidos, nós, seres humanos cultos, somos cada vez menos donos do nosso destino, o futuro aparece-nos ameaçador, não havendo garantia de sobrevivência da espécie humana.

As ciências sociais devem demonstrar, acima de tudo, o seu interesse em antecipar-se, captar a direcção de mudança, e expor uma visão dos novos fenómenos que afectam a segurança humana de maneira a que possam contribuir para se compreender qual é o novo papel do Estado e da comunidade neste século XXI. Numerosos fenómenos sociais, vale a pena repetir, desde a necessidade de segurança ambiental, de saúde, de alimentação, segurança política e jurídica para a protecção de minorias, para a protecção das mulheres, etc., têm no novo conceito de segurança humana um espaço para a investigação e compreensão deste novo conceito da sociedade do risco. Os tempos em que a segurança do Estado proporcionava tranquilidade suficiente parecem estar a mudar substancialmente. Hoje, a segurança é um problema do Estado, dos outros, nosso, da polícia, da comunidade? De todos? $O$ que é a segurança para cada um? Quem a garante? A insegurança é uma invenção dos "media", um mito? Quais são as verdadeiras ameaças? Segurança e delito são a mesma coisa?

Os anos finais do século XX foram um período histórico no qual se percebeu com maior nitidez as rápidas mudanças em muitas frentes: económicas, sociais, políticas, ambientais e culturais. Muitas destas transformações são, em larga medida, fruto do processo de globalização e de uma sociedade que já não se sente segura com os paradigmas da modernidade. Enfrentamo-nos, pois, perante novas oportunidades para as pessoas e os povos, mas que também deram lugar a novas desigualdades, medos e inseguranças.

"Estamos perante uma autêntica «Revolução Urbana» que sucede a «Revolução Industrial» que, por sua vez, sucedeu à «Revolução Agrícola» e recebe a herança histórica da Civilização Greco-Romana do mundo mediterrânico," assevera Gonçalo Ribeiro Teles que, invocando a falta de planeamento e de cartografia das vulnerabilidades sociais, se refere à cultura do "subúrbio", a qual caracteriza actualmente a actividade urbana entre nós (Teles, 2001:25).

A construção faz-se em qualquer lugar, mesmo que este seja impróprio para tal. A desmesurada altura dos edifícios é a causa de graves problemas de insegurança, vandalismo, criminologia e roubo. A convivência social e a solidariedade social nesses "acampamentos" de cimento armado também dificilmente se estabelece.

O modelo suburbano, prossegue Ribeiro Teles, (2001:27) torna a estrutura metropolitana um labirinto, onde dificilmente se circula fora dos grandes eixos viários; a circulação da água pluvial não tem percursos adequados; o contacto com a vida silvestre não se verifica e o percurso a pé não é possível.

Não são criados espaços verdes residuais, deixados pelas construções amontoadas, e não são os parques urbanos limitados por um perímetro desligado de todo o contexto ecológico e regional que resolvem os grandes problemas resultantes da ausência de uma estrutura ecológica.

$\mathrm{Na}$ "cidade-região" do século XXI, não podem deixar de existir as ribeiras, as sebes e matas de protecção, os percursos pedestres, o recreio, as hortas, constituindo "contínuos naturais" harmoniosamente intercalado com os contínuos edificados. Em Portugal é necessário modificar o modelo suburbano por um planeamento em que figure a agricultura urbana de frescos.

As "áreas metropolitanas" não podem deixar de incluir no seu contexto territorial a produção de frescos, a protecção ambiental, o recreio a céu aberto e a "cidade" nas suas múltiplas funções sociais e culturais.

Não se compreende por isso que a Lei de Bases de Ordenamento do Território ainda estabeleça a classificação do solo em "urbano" ou "rural", abrindo a porta à especulação com prejuízo para uma política territorial equilibrada e sustentável (TELES, 200 1:28). 
As controvérsias em torno dos riscos têm tido duas ordens de consequências: a politização dos riscos, acompanhada da reclamação crescente pelos cidadãos de modos mais democráticos e participativos de os gerir, e uma maior percepção pública das condições de produção do conhecimento científico e das incertezas nele envolvidas.

Os "novos riscos" são, em grande parte, riscos "globais". Os riscos ambientais e de saúde pública mais em foco nos últimos tempos transcendem as fronteiras nacionais. Por exemplo, a propagação de doenças emergentes (como a Sida, a pneumonia atípica) ou a disseminação de produtos alimentares contaminados (fot. 5) acompanham o comércio de mercadorias, a mobilidade das pessoas, a circulação das tecnologias. A omnipresença do risco na sociedade contemporânea encontra-se, assim, estreitamente associada à sua globalização (Gonçalves, 2002:6).

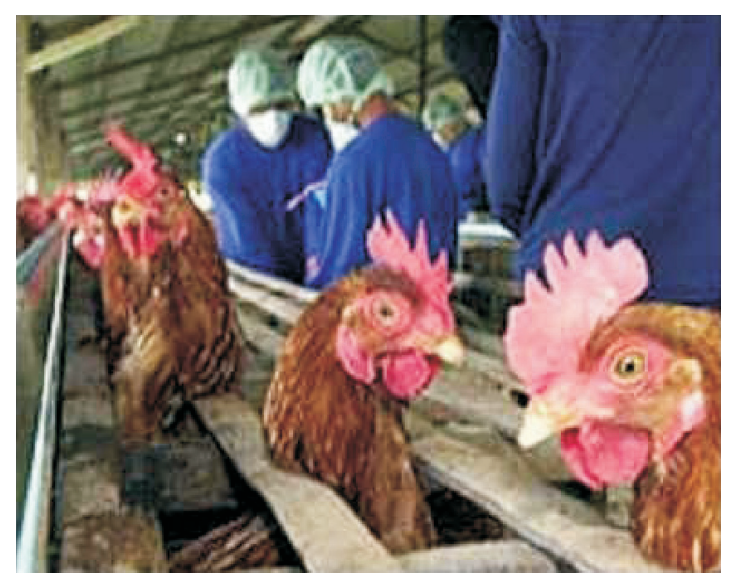

Fot. 5 - Gripe das Aves (fonte: http://fotoseimagens.blogs.sapo.pt).

Num quadro de instabilidade e incertezas, a segurança assume um novo conceito, abrangendo não só a segurança individual ou nacional, mas sim a segurança global, motivando a redefinição dos sistemas de informações e o papel das forças armadas, das forças de segurança e das forças de socorro e de assistência às populações.

Hoje a segurança vê o seu conceito ser alargado a domínios como a política, a economia, a diplomacia, os transportes, as comunicações, a saúde, o ambiente, etc., onde a imprevisibilidade aumenta as condições de ocorrência de fenómenos com consequências directas ou indirectas sobre as populações. $\bigcirc$ aumento populacional (com forte desequilíbrio social), as migrações (com reflexos étnicos e religiosos), as questões ambientais (clima, alimentação e escassez de recursos naturais), o desenvolvimento tecnológico e a sociedade de informação são factores importantes para repensar e redefinir a segurança na sociedade de risco (Pureza, 2002:45).

Perante a sensação de vulnerabilidade da sociedade, existe um conjunto de novas ameaças e riscos que agudizam o sentimento de insegurança das pessoas e assiste-se à crise do Estado Nação e do modelo estatocêntrico que o sustentou. "O sistema estatocêntrico vê limitadas as suas capacidades para enfrentar alguns problemas como desequilíbrios ambientais globais, a distribuição assimétrica da riqueza, a explosão demográfica, a emigração clandestina ou o risco de confrontação nuclear. $\bigcirc$ paradigma estatocêntrico não tem capacidade explicativa e terapêutica para as novas realidades que decorrem do processo de globalização" (FALK, 2002:72).

De facto, uma das mais duras aprendizagens que os EUA e os Estados Nação aliados pareceram aprender com o 11 de Setembro é que o inimigo que enfrentavam não era um Estado Nação soberano, mas uma rede, sem centro, que ameaça constantemente os limites entre interior e exterior, entre o global e o local. Como bem assinala Richard Falk, (2002:72-75) os fundamentos estruturais e reguladores da ordem mundial, parecem cada vez mais incapazes de oferecer um mínimo de segurança a muitos povos do planeta.

"El Estado está siendo sutilmente deformado, en cuanto a instrumento de bienestar humano, por la dinámica de la globalización que lo impulsa, en diferentes grados, hacia una relación de subordinación respecto a las fuerzas globales del mercado. En parte como repuesta a esto y en parte como resultado de las deficiencias del secularismo como fuente de realización humana, en muchos terrenos el Estado está perdiendo también su capacidad para procurar los componentes sociales, económicos y materiales de la seguridad dentro de sus proprias fronteras." (FALK, 2002:75)

Esta perda de capacidade dos Estados tende, em si mesmo, a perturbar o próprio processo de governabilidade interna, levando alguns governos a diminuir os programas sociais e de bem estar dos cidadãos, debaixo do estandarte da "lei e da ordem" num eufemismo para enquadrar/legitimar a pena capital, o aumento das forças policiais, melhor e mais sofisticado armamento e prisões maiores. Os Estados e as suas sociedades dependem mais que nunca dos seus actos e omissões de outros, para a segurança das suas gentes e, às vezes, para a sua própria sobrevivência. Um aspecto particularmente relevante 
acerca da relação entre direito e controle na Internet mostra, de igual modo, a fragilidade da soberania dos Estados. A liberdade da rede converteu-se numa manifestação decisiva das liberdades públicas, (...) impondo uma revisão do paradigma da soberania dos Estados, sobretudo da sua soberania na Internet. Assim, o conceito de soberania na Internet passa do sujeito Estado para o sujeito "usuário", incluso para o sujeito "red" (Moles, 2004:20-21).

Em rigor, no quadro da mudança provocada pela Internet, o mundo dos Estados Nacionais parece já não existir. Situamo-nos, pois, no marco do debate contemporâneo no qual se volta a colocar algumas perguntas fundamentais: qual é o objecto da segurança: os povos, os Estados, a comunidade internacional, o indivíduo?; quem define a segurança?; quais são as condições da segurança?; segurança de que ameaças?; com que valores?; com que significado? Afinal, o que está a surgir ou já terá surgido? Estaremos à beira de um mundo sem lei, face às rupturas dos limites da segurança interna e externa, nacional e internacional, global e local?

Assumindo a complexidade da realidade contemporânea podemos dizer, com Edgar Morin que, "toda a evolução é o logro de uma derivação cujo desenvolvimento transforma o sistema onde ela mesma nasceu: desorganiza o sistema reorganizandoo. A incerteza irremediável da história humana. A história humana que foi e continua a ser uma aventura desconhecida" (Pereira 2006:37).

A humanidade não pode evitar o facto de que tenhamos sempre, como tarefa, aprender a enfrentar as incertezas e as adversidades que comporta $\circ$ existir, o viver.

No nosso mundo, a estabilidade política e a segurança do Estado estão ameaçadas por muitos factores que excedem as capacidades inerentes da sua própria soberania. A pobreza, as doenças transmissíveis, a degradação do ambiente, as crises económicas, o terrorismo, as armas de destruição massiva, o crime organizado internacional, há que vê-los em termos das tendências globais e forças que afectam os indivíduos e as comunidades, perante os quais o Estado se encontra limitado para os evitar e proteger os seus cidadãos - eis a crise do Estado Estatocêntrico, o Estado que não pode fazer tudo sozinho.

Essas tendências incluem, ainda, a pressão sobre os recursos renováveis, tráfico de drogas, tráfico de seres humanos, o rápido desenvolvimento do capitalismo selvagem, desigualdade, miséria humana e a epidemia da sida e muitas outras - vulnerabilidades sociais geradoras de inseguranças. Estará o Estado impotente perante estas vulnerabilidades? Poderá superá-las sem uma efectiva cooperação internacional?

A análise que vimos fazendo coloca a seguinte questão-chave: como fazer com que o Estado abandone a sua actual predisposição para uma globalização baseada no mercado e conseguir que manifeste um maior grau de receptividade para uma globalização orientada para as pessoas, capaz de dar corpo a uma governabilidade humanizada do planeta? (FALK, 2002:75)

Como fazer com que, a segurança básica, os direitos humanos, os temas sociais globais, como a protecção do ambiente, sejam resolvidos cooperativamente? Esta vulnerabilidade é "um sinal dos tempos" ou um traço característico desta época, posto que não se sabe donde podem proceder os perigos que não põem em risco unicamente o Estado, mas que podem atentar directamente contra a vida individual de cada cidadão?

Para concluir importa referir que embora muitas vezes se tenha considerado a globalização como sinónimo de americanização, neste mundo de liberalização crescente, vão nascendo numerosas iniciativas e actividades que se apoiam na necessidade de extensão dos novos direitos sociais e de prevenção de riscos, dando sentido a esta nova ideia de segurança humana como superação de uma visão estatocêntrica, frente a uma visão humanocêntrica da segurança, ou seja, um conceito que permite integrar as diferentes dimensões que encerra a insegurança do ser humano.

O carácter multidimensional da segurança humana faz com que o desafio principal para a administração pública, hoje em dia não seja centrarse não tanto na segurança em sentido estrito, mas antes abordar de forma equilibrada e integrada todos os aspectos da segurança humana, os quais estão relacionados entre si.

Em última instância, a estabilidade e a segurança somente se podem obter corrigindo e eliminando as causas subjacentes à violência e à guerrilha urbanas (fot. 6), assim como as causas inerentes à prevenção dos riscos de saúde e da vida diária. Estas causas não podem ser alheias aos objectivos dos governos e da administração pública, devendo proporcionar protecção geral aos cidadãos, com a participação social desses mesmos cidadãos e cidadãs. 


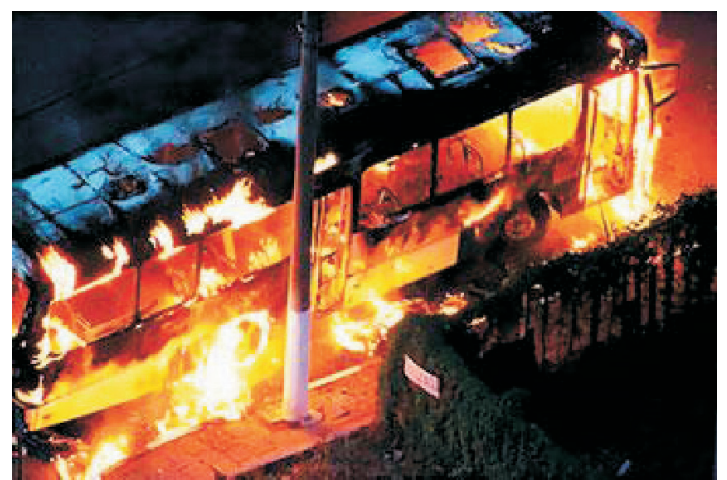

Fot. 6 - Guerrilha urbana (fonte: www.sindmetalsjc.org.br).

Quais as principais vulnerabilidades em Portugal?

Como bem assinala Severiano TeIXEIRA (2004:5), "até há bem pouco tempo a Segurança Internacional e a Segurança Interna eram realidades distintas e bem delimitadas. A Segurança Internacional era uma questão, exclusivamente, entre Estados que dispunham para lhe fazer face de dois instrumentos fundamentais: a diplomacia para o tempo de Paz e as forças armadas para o tempo de Guerra. A Segurança Interna era outra coisa que se desenrolava e resolvia, exclusivamente, no interior dos Estados. Era o problema da criminalidade e da insegurança, face ao qual o Estado dispunha de dois outros instrumentos: o direito penal e a repressão policial".

Hoje, esta realidade é muito mais complexa e os limites muito mais fluidos, porque embora continuem a existir ameaças à segurança que são, exclusivamente, internas e ameaças à segurança que são, exclusivamente, externas, coexiste, simultaneamente, um espectro muito alargado de ameaças que têm origem no exterior, que atravessam as fronteiras dos Estados, que escapam ao seu controlo e se manifestam no interior dos Estados.

"São ameaças transnacionais como o crime organizado, o narcotráfico, o terrorismo transnacional e outras, que determinam a transnacionalização do fenómeno da segurança e exigem não só novas perspectivas de análise, mas também e sobretudo novas políticas de segurança" (TEIXEIRA, 2004:5).

Ora, de acordo com os actuais paradigmas das ameaças e dos riscos, e para lhes fazer face, a Segurança é de âmbito mais alargado, envolvendo mais valências e capacidades que a Defesa; esta é uma componente da Segurança Alargada, que integra outras dimensões, designadamente a Protecção Civil.
Hoje, no quadro da Segurança Humana, o objectivo da grande segurança é a protecção do cidadão, modelo humanocêntrico, e não apenas do EstadoNação, Território, ou seja, o Estado Estatocêntrico, daí que tenham tanta importância ameaças como o Terrorismo Transnacional, a Criminalidade Organizada, as epidemias globais, etc.

No fundo, a segurança é uma, como bem assinala o Senhor General Garcia Leandro, devendo ser concebida no topo do Estado, sendo responsável pela sua concepção o chefe do Governo, o que significa que as suas componentes (segurança interna, segurança externa e segurança, protecção e socorro) não podem ser desenvolvidas, trabalhadas e implementadas de modo parcial ou isolado (LEANDRO, 2007:88).

Os Ministérios da Soberania (Negócios Estrangeiros, Defesa, Administração e Justiça), assinala o mesmo General, têm áreas de sobreposição e daí que não se possa continuar a trabalhar em cilindros estanques e numa relação apenas verticalizada. Por outro lado, para que possa haver segurança deve existir coordenação entre os sistemas e dar àqueles que se encontram no terreno todas as informações necessárias de modo transversal. $\mathrm{O}$ mesmo deve ocorrer na área operacional executiva. "O nosso problema é existirem pessoas com funções conjunturais de responsabilidade em matérias de segurança (...) que julgam que a questão se esgota no seu serviço; olham apenas para o seu umbigo e têm enormes dificuldades em trabalhar em conjunto" (LEANDRO, 2007:88).

Não tendo Portugal sido atingido, felizmente, por acidentes ou catástrofes do tipo Nova lorque, Madrid e Londres, sem esquecer Bali, Rabat, Istambul ou Nova Orleães, é de perguntar até que ponto estaríamos preparados para responder com o mínimo de eficácia e prontidão a tais situações?

Segundo o General Garcia Leandro, "a resposta só pode ser um rotundo NÃO. É com vergonha que o reconheço, bastando recordar o que se passou em 2002, com o desastre da Ponte de Entre-os-Rios em Castelo de Paiva (fot. 7), quer pelas razões que estiveram na sua origem, quer pelo modo amador, assustado e improvisado como essa crise foi gerida. No mundo actual não se pode funcionar naqueles moldes" (LEANDRO, 2007:16). 


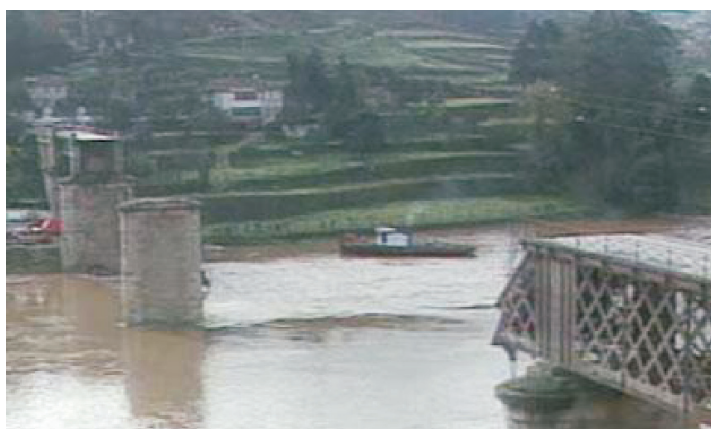

Fot. 7 - Desastre da Ponte Entre-os-Rios (fonte: www.rtp.pt).

Mas, todos os anos, somos vítimas das consequências das mudanças climáticas que estão em curso, tanto durante o tempo quente, como as grandes chuvadas, não estando só em causa o nosso interior e as florestas, mas também a nossa costa que, se bem tratada, é uma das áreas que mais receitas pode proporcionar e que tem vindo a ser progressivamente destruída. E tudo se repete anualmente sem grandes melhorias significativas. Grande parte dos desastres que têm afectado o nosso ecossistema é consequência da falta de um correcto, devidamente cumprido e acompanhado ordenamento territorial. "Se as Autarquias têm sido responsáveis por grande parte do desenvolvimento do País, reconhecimento que deve ser feito são, em muitos casos, as grandes responsáveis, não só pelos gravíssimos atentados ambientais que têm ocorrido e que estão à vista de todos, como também pela falta de prontidão da Protecção Civil nas suas áreas de responsabilidade. Estamos, como sociedade nacional, já a pagar o preço de omissões e de decisões desastradas, o que se pode agravar no futuro" (LEANDRO, 2007:16).

\section{Que Protecção Civil temos nós?}

No quadro da Lei de Bases n. $-27 / 2006$ de 3 de Julho, a protecção civil é a actividade desenvolvida pelo Estado, Regiões Autónomas e autarquias locais, pelos cidadãos e por todas as entidades públicas e privadas com a finalidade de prevenir riscos colectivos inerentes a situações de acidente grave ou catástrofe, de atenuar os seus efeitos, proteger e socorrer as pessoas e bens em perigo quando aquelas situações ocorram.

Entre outros, são objectivos (fig. 1) fundamentais da protecção civil:

- Prevenir riscos colectivos e ocorrência de acidente grave ou de catástrofe deles resultante;

- Atenuar os riscos colectivos e limitar os seus efeitos no caso das ocorrências.

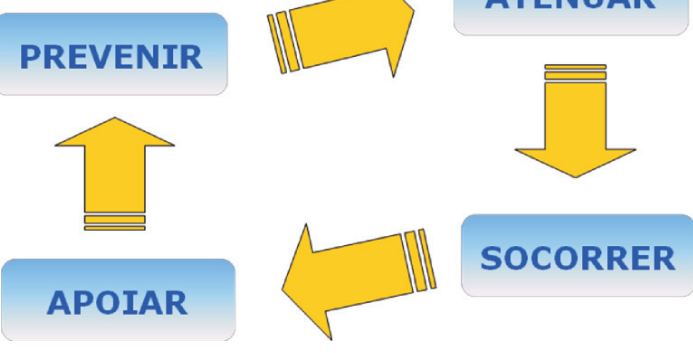

Fig. 1 - Objectivos da Protecção Civil.

Estamos preparados para responder a estes desafios de socorro, designadamente em termos de inundações (fot. 8), explosões e incêndios industriais (fot. 9), em edifícios de grande altura (fot. 10) e florestais (fot. 11 )?

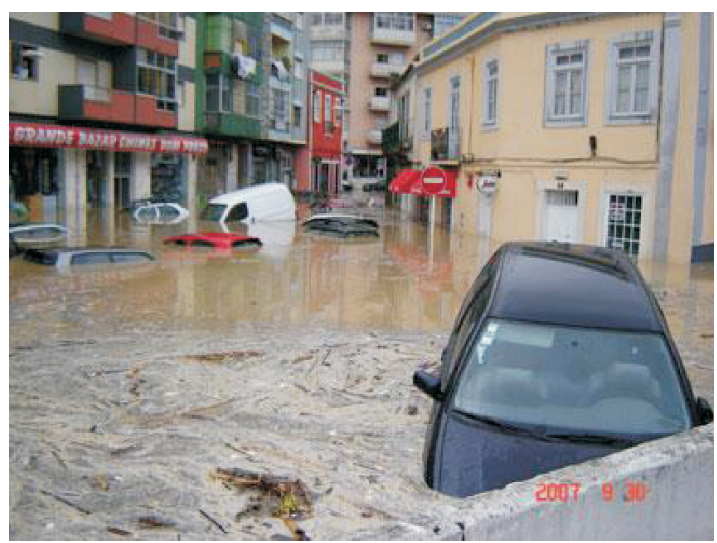

Fot. 8 - Inundações

(fonte: http://divagacoesaoluar.files.wordpress.com).

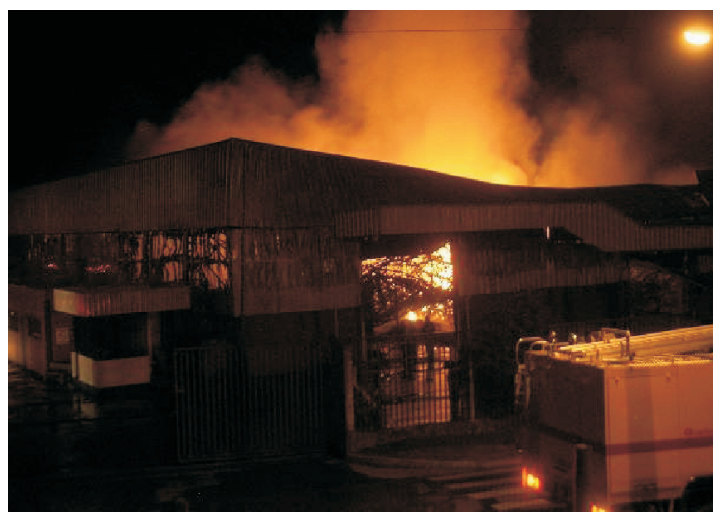

Fot. 9 - Explosões e Incêndios industriais (fonte: http://g l globo.com).

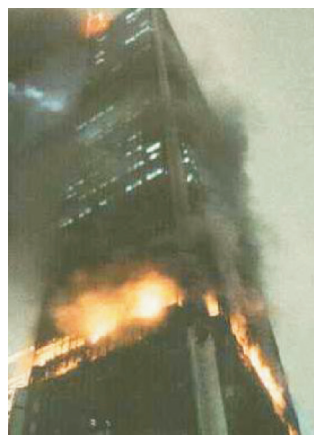

Fot. 10 - Incêndios em edifícios de grande altura (fonte: http:// 911 research.wtc7.net/talks/b7/docs/ la_fire_lg_c.jpg ). 


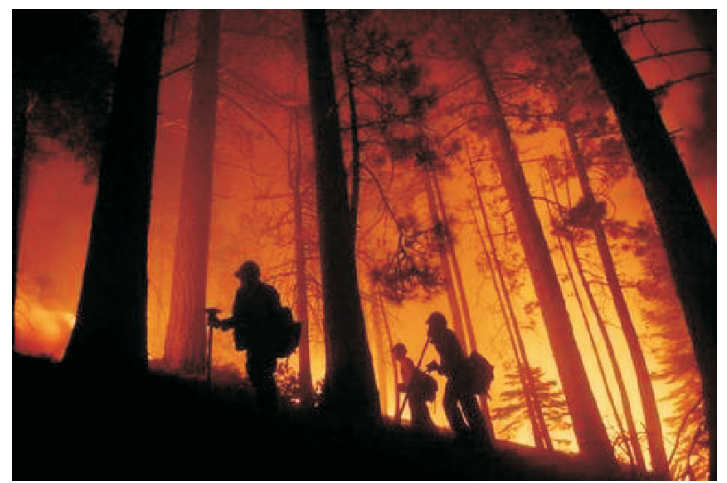

Fot. 8 - Incêndios florestais (fonte: www.shm.com.au).

A actividade da protecção civil, exerce-se nos seguintes domínios:

a) Identificação, levantamento, previsão, avaliação e prevenção dos riscos colectivos; - Quem faz? Existe uma Carta de Risco Nacional?

b) Análise permanente das vulnerabilidades perante situações de risco; - Quem procede a esta análise? Existe uma cartografia das vulnerabilidades sociais, por ex.?

c) Estudo de soluções para "controlo" dos Riscos e respectiva intervenção perante a iminência ou ocorrência dos mesmos. Quem faz?

d) Existe o risco quantificado numa dada comunidade (por exemplo: município, distrito ou região), por forma a que se elaborem planos de Emergência (de carácter geral ou especial) e, como tal, alertem, preparem e habilitem as próprias comunidades para respostas céleres e eficazes em situação de emergência?

e) O processo de planeamento de emergência é multidisciplinar e plurisectorial, em que o nível inferior (municipal) é apoiado pelo nível superior distrital, envolvendo entidades locais, regionais ou nacionais, partilhando informação e cooperando de acordo com os riscos envolvidos e respeitando o princípio da proporcionalidade?

Em suma, pode haver um sólido e seguro planeamento de emergência sem um adequado processo de gestão de risco?

Não pode. A implementação de um processo de gestão de risco (em que a comunicação e a consulta são imprescindíveis para garantir o empenho/ participação dos parceiros envolvidos) torna-se decisivo no processo de planeamento de protecção civil, possibilitando agilizar procedimentos e rentabilizar os recursos humanos e materiais necessários para as operações de emergência, tendo como objectivo a - segurança da comunidade.

Sem este processo de identificação e avaliação dos riscos, como sabemos que estamos em perigo e se estamos ou não protegidos e preparados contra os riscos existentes?

Como saberemos o que nos ameaça, como poderemos ou não proteger-nos e como deveremos reagir no caso de ameaça se concretizar?

Como saberemos se se justifica ou não montar um sistema de gestão de crises e para que fim estaremos realmente a fazê-lo?

Quais os riscos que aceitamos, quais os que não aceitamos e relativamente a estes últimos, quais os que conseguimos eliminar ou apenas reduzir?

Que medidas iremos adoptar/implementar para reduzir as vulnerabilidades identificadas?

Se o lugar do cidadão no quadro do conceito de segurança humana "é no coração da protecção civil", o que está a ser feito para desenvolver a capacidade de antecipação, antevendo, prevendo e preparando, habilitando as comunidades para a sua própria defesa?

Se a protecção Civil é uma responsabilidade partilhada, é esta, internacionalmente, a actual linha de força, o que está a ser feito entre nós, em ordem a uma cultura e pedagogia da Protecção Civil?

É perceptível, entre nós, a partilha de responsabilidade entre cidadãos, empresas, municípios, governo, comunicação social, organizações da economia social, nas principais dimensões de Protecção Civil, que são a prevenção, a protecção e a preparação para a emergência? Como se faz?

O estabelecimento de uma Cultura de Protecção Civil significa que a população adopte, individual e colectivamente, valores, atitudes e comportamentos fundados nos seguintes moldes:

- A tomada de consciência sobre os riscos existentes;

- A necessidade de se proteger e de se preparar face à manifestação eventual dos riscos;

- A responsabilidade de cada um perante esses riscos;

- A solidariedade que uma moderna sociedade deve fazer prova.

Significa também poder contar com o empenho de cidadãos informados, com conhecimentos sobre os perigos, sobre as normas de prevenção e autoprotecção e capazes de se integrarem na organização colectiva de resposta à emergência (MARTINS, 2004:34). 
Treinar as pessoas é garantir o seu nível de informação e formação, motivação e empenhamento e a criação de mecanismos colectivos de intervenção; Quem faz? O que deve fazer o Estado?

Estado tem um papel fundamental a desempenhar no que concerne à regulação e orientação cultural e pedagógica de uma moderna Organização de Protecção Civil:

- Elaborando estratégias de prevenção, protecção, resposta e reabilitação;

- Afectando os meios necessários;

- Recorrendo, quando necessário, a meios de excepção;

- Sensibilizando, informando, formando e responsabilizando a população;

- Articulando políticas com as Associações provenientes da Sociedade Civil.

De tudo isto, o que está a ser feito, por quem, onde e como?

Ao nível da estratégia de investigação do risco, parece hoje claro que é na base da Organização da Protecção Civil - o Município - que deve centrar-se o maior esforço.

Qual é então o principal dispositivo ou forças de socorro de que dispõe o sistema de Protecção Civil?

"A componente operacional do sistema são os bombeiros voluntários, são a espinha dorsal (fig. 2). Eles cumprem mais de $90 \%$ das missões de protecção civil e tendem a ser profissionais na sua acção. São voluntários, mas têm de tender a estar disponíveis para receber uma formação cada vez mais abrangente e qualificada. Não me parece que exista o risco de o sistema soçobrar por estar assente em voluntários.

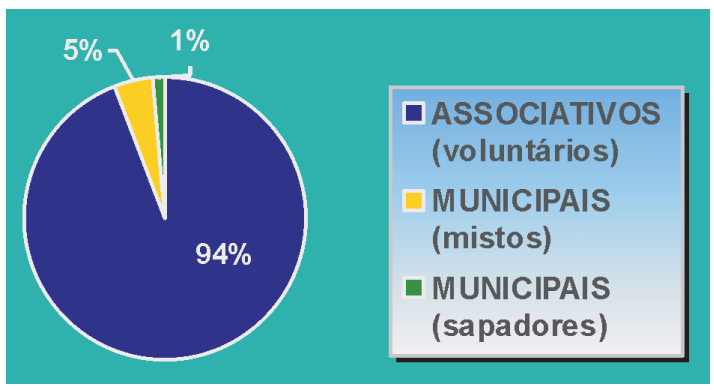

Fig. 2 - Dispositivo de socorro ao nível dos bombeiros.

Eles dependem de nós sobre o ponto de vista operacional e isso decorre de uma situação em que, até hoje, não tem havido quebras de solidariedade. ○ que está em causa não é o cooperativismo dos bombeiros ou o cooperativismo da GNR, a missão é proteger as pessoas e o património, por isso creio que os protocolos não podem deixar de ser cumpridos." (A. CRUz, 2007:34)

Se o socorro depende, em cerca de $90 \%$, dos Corpos de Bombeiros Voluntários, há condições para agir com prontidão e eficácia na 1. ำ intervenção?

Quando falamos apenas em dependência operacional, quem garante a mobilização dos efectivos e a sua formação? Quem manda nas Associações que suportam os Corpos de Bombeiros? A quem prestam contas?

Não é verdade que o sistema de resposta assente no voluntariado funcionasse bem quanto à modernização. Existe uma lei nova. Quantos municípios estão preparados para a protecção civil ou têm condições para o desenvolvimento de padrões aceitáveis de prevenção, protecção e resposta a situações de crise? Que papel está reservado à figura (tão contestada por alguns) do Comandante Operacional Municipal?

E como estamos quanto aos dispositivos de resposta a situações de socorro e de emergência?

O artigo 46. da Lei de Bases da Protecção Civil, designa como agentes de Protecção Civil com as suas atribuições próprias:

a) Corpos de bombeiros;

b) As forças de segurança;

c) As forças armadas;

d) As autoridades marítima e aeronáutica;

e) O INEM e demais serviços de saúde;

f) Os sapadores florestais.

No n. .4 deste artigo, refere-se que os agentes se articulam operacionalmente nos termos do SIOPS (Sistema Integrado de Operações de Protecção e Socorro).

Se o sistema assente no voluntariado garantisse, com prontidão, a 1. ․ intervenção, qual a necessidade do Governo em propor a criação de 200 equipas de primeira intervenção nos corpos de bombeiros?

Se existe falta de disponibilidade (não de vontade, nem de altruísmol para a $1 .^{\underline{a}}$ intervenção, haverá disponibilidade para a formação?

Não é verdade que, em muitos quartéis, a instrução e o treino não é levada à prática com regularidade?

Como é que podemos ter bombeiros qualificados se não houver, por parte dos comandantes, uma 
política adequada de formação contínua semanal (no mínimo)?

Existe alguma lógica operacional/técnica explicita para a actual distribuição geográfica dos corpos de bombeiros? A formação e os equipamentos estão normalizados, quer se trate de corpos de bombeiros voluntários ou profissionais?

Como se justifica termos apenas 24 bombeiros voluntários certificados, ou seja, habilitados com o Certificado de Aptidão Profissional (CAP), aprovado pela Portaria n.․ 247/2004 de 6 de Março, segundo dados facultados pela própria ENB?

É possível enumerar muitas questões sobre as vulnerabilidades do sistema de socorro, desde a falta de prevenção de riscos profissionais dos agentes de socorro, à disparidade de formação de muitos Corpos de Bombeiros, à falta de homogeneidade dos programas formativos, à formação sem consequências, etc. No entanto, em boa medida, todos concordamos que a formação (séria) competente é o principal vector de mudança nos bombeiros?

Digamos não à falta de Qualidade. Digamos sim ao Voluntariado com espírito profissional, enquadrado em novos padrões organizativos e operacionais e à sua pedagogia, "porque, só se constrói o que não é de ninguém, só se destrói o que não se ama".

São muitas as ocasiões em que os indivíduos e as comunidades podem contribuir directamente para identificar e pôr em prática soluções entre os múltiplos aspectos que supõem insegurança humana. A segurança do Estado e a segurança humana reforçam-se e dependem mutuamente uma da outra. Velando pela segurança humana ampliam-se as verdadeiras liberdades de que desfruta a pessoa. Fomentar a capacidade da pessoa para trabalhar em seu nome e em nome dos outros é uma das premissas deste pensamento acerca da segurança. Ora, fomentando essa capacidade diferencia-se a segurança humana, da segurança do Estado. A habilitação das pessoas para a segurança é importante já que desenvolve o potencial que cada um tem como indivíduo ou como comunidade. Favorecer essas capacidades e reconhecer o seu papel é um dos reptos do novo "estado regulador" que terá que gerir reconhecer e promover o papel dos movimentos e da participação dos cidadãos na sua própria segurança.

O caso ainda recente do Prestige demonstra que começam a existir fortes sinais de civismo e vitalidade; que a comunidade não espera, sabendo que é impossível que o Estado intervenha e que resolva tudo. Não é necessário, menos estado e mais mercado, mas integrar a comunidade na gestão. Ou seja, o Estado democrático, sem reforço, passa pela potenciação da comunidade integrada na gestão pública, quer dizer um modelo de Estado Comunidade.

\section{Referências Bibliográficas}

Amaro, António (2005) - "Consciência e Cultura do Risco nas Organizações", Territorium, 12.

BECK, Urich (1992) - "Risk Society". To Wards a New Modernity, Londres: Sage.

BECK, Ulrich (2004) - "Poder e Contrapoder da Era Global". La Nueva Economia Política Mundial, Paidós, Barcelona.

Cruz, Arnaldo (2007) - "A missão é proteger as pessoas e o património". Alto Risco, Revista da Associação Nacional dos Bombeiros Profissionais, n. -26, p. $32-35$.

FALK, J. R. (2002) - "La globalizacion Depredadora", Siglo XXI, Madrid.

LEANDRO, Garcia (2007) - "O Estado, o Cidadão e a Segurança. Novas soluções para um novo Paradigma", Revista Segurança e Defesa, 2, pp. 16-17.

LeandRo, Garcia (2007) - "Da Defesa à Grande Segurança", Revista Segurança e Defesa, 3, pp. 25 - 30.

GIDDENS, Anthony (1998) - "Risk Society: the Context of British Politics" in Jane Franklin ed., The Politics of the Risk Society. Londres, Polity Press, pp. 23-24.

Gonçalves, M. Eduarda (2003) - "Os Novos Riscos", Actas do IX Cursos Internacionais de Verão de Cascais, Ed. Câmara Municipal de Cascais.

Mendes, J. M. Oliveira (2007) - "Vulnerabilidade Social, Risco e Segurança das Populações: o Papel do Planeamento", in Riscos Públicos e Industriais, C. Guedes Soares, A. P. Teixeira e P. Antão (Eds), Edições Salamandra, Lisboa, 2007.

Moles, R. J. (2004) - “Derecho y Controle en Internet". La Regularidad de Internet. Ariel Derecho, Barcelona.

PenA, António (2006) - "A Comunicação como Forma de Reduzir a Incerteza em Situações Complexas de 
Decisão", Processos Decisórios Envolventes da Integração dos Corpos de Bombeiros, no Sistema de Protecção Civil Português, dissertação de Doutoramento em Ciências de Comunicação, Universidade Nova de Lisboa, doc. não publicado. Pereira, João Pablo (2006) - La Securidad Humana. Editorial Ariel, S. A., Barcelona.

Pureza, J. M: (2002) - El Patrimonio Comum de la Humanidade, Hacia num Direito Internacional de La Solidariedad. Editorial Trotta, Madrid.

TeixeIRA, Severiano (2004) - in Actas dos X Cursos Internacionais de Verão de Cascais (7 a 12 de Julho) Cascais: Câmara Municipal, vol. 4, p. 5.

Teles, G. Ribeiro (2001) - in Actas dos VII Cursos Internacionais de Verão de Cascais (3 a 15 de Julho de 2000). Cascais: Câmara Municipal de Cascais, 2001, Vol. 4 pp. 25 a 28. 